\title{
Cisto Dermóide Simulando Neoplasia Retro-Retal
}

\author{
Dermoid Cyst Simulating Retro-rectal Neoplasia

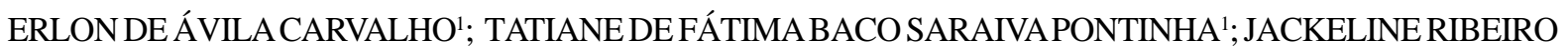 \\ OLIVEIRA ${ }^{2}$;EUSTÁQUIO DECARVALHO BRAGA²; JOSÉ ADEMAR BALDIM ${ }^{3}$. \\ 1. Acadêmicos de medicina da UNIFENAS - Alfenas; ${ }^{2}$ Residentes de Cirurgia Geral do HUAV-Alfenas; \\ 3. Cirurgião geral, coloproctologista e professor da disciplina de Coloproctologia do HUAV - Alfenas.
}

CARVALHO EA; PONTINHA TFBS; OLIVEIRA JR; BRAGA EC; BALDIM JA. Cisto Dermóide Simulando Neoplasia Retro-Retal. Rev bras Coloproct, 2007;27(3): 328-329.

RESUMO: Cisto dermóide é uma formação tumoral constituída por um enclausuramento epidérmico contendo folículos pilosos, glândulas sebáceas e localizadas geralmente no pescoço.

Descritores: Cisto dermóide; neoplasia; benigno; retro retal; toque retal.

\section{INTRODUÇÃO}

Os cistos dermóides são formações tumorais benignas constituídas de revestimento epidérmico, o conteúdo compõe-se de queratina, sebo, freqüentemente pêlos e raramente cartilagem e ossos ${ }^{1}$.São nódulos subcutâneos cujo tamanho varia de 1 a $5 \mathrm{~cm}$, de consistência branda, localizados na área de fendas embrionárias, como regiões periorbitárias, pescoço, região supra-esternal e cabeça ${ }^{2}$. Apresentamos um caso de cisto dermóide simulando uma neoplasia retro-retal.

\section{RELATO DE CASO}

Paciente M.L.P.M., 64 anos, do sexo feminino, procurou o ambulatório do Hospital Universitário Alzira Velano em 21/10/05 queixando-se de alteração do hábito intestinal há cerca 4 meses e ao exame protológico de inspeção, apresentou um abaulamento em região perineoinguinal, no qual foi evidenciado ao toque retal uma massa para-retal na região látero anterior esquerda, com aproximadamente $10 \mathrm{~cm}$ de diâmetro.

Realizou a tomografia computadorizada de pelve com contraste retal que evidenciou a presença de um tumor retro-retal, sendo solicitado o CEA cujo o resultado foi $2,2 \mathrm{ng} / \mathrm{ml}$.
No dia 04/01/06 foi realizada excisão cirúrgica com retroperitoniofixação, sendo retirada uma estrutura cística medindo cerca de $10,5 \times 7,5 \mathrm{~cm}$ (figura 1) e enviado o material cirúrgigo para anátomo-patológico, cujo o laudo mostrou "formação cística com parede constituída por epitélio plano estratificado com diferenciação em camadas granulosa e córnea", compatível com cisto dermóide e ausência de sinais de malignidade (figura 2).

A paciente evoluiu bem, tendo boa recuperação, com alta hospitalar no $5^{\circ}$ dia de pós-operatório.

\section{DISCUSSÃO}

Os cistos dermóide são cistos formados por revestimento epidérmico ${ }^{3}$, a cápsula é epidérmica com anexos rudimentares e a massa cística é constituída por sebo e queratina, às vezes com pêlos ${ }^{2}$.

Histologicamente, são divididos em três tipos; de acordo com seu conteúdo; se não há anexos dérmicos presentes, o cisto é dito epidermóide; se anexos como glândulas sebáceas, glândulas sudoríparas ou folículos pilosos estão presentes, é denominado dermóide propriamente dito; e o terceiro tipo é denominado teratoma, sendo formado por revestimento contendo estruturas derivadas das três camadas germinativas ${ }^{3}$.

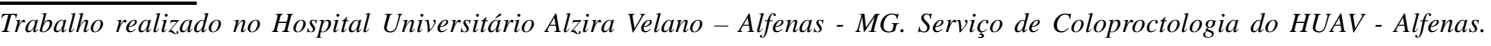




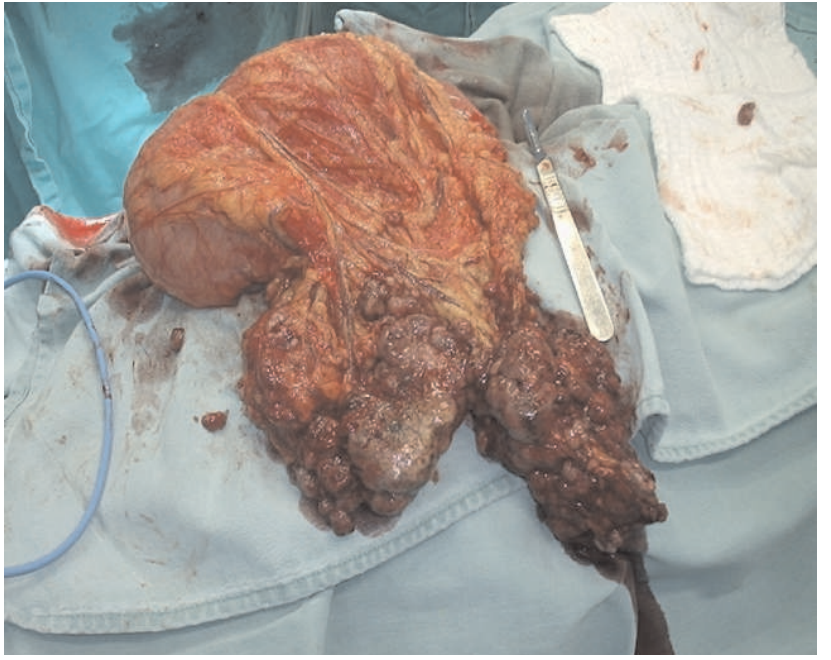

Figura 1 - Visualização macroscópica de uma estrutura cística medindo cerca de 10,5x7,5 cm, com trama vascular evidente.

Aproximadamente $1 \%$ desses tumores têm elementos malignos, em geral carcinoma de célula escamosa ${ }^{4}$.

A patogênese dos cistos dermóides permanece obscura, existindo duas teorias para explicar sua origem. A primeira é a teoria congênita, a qual sugere que o cisto se origina de tecido pluripotente mediano, encarcerado durante a fusão dos $1^{\circ}$ e $2^{\circ}$ arcos branquiais, na $3^{\circ}$ e $4^{\circ}$ semanas de vida intra-uterina. A segunda é a teoria adquirida, na qual ocorreria implantação de células epiteliais nos tecidos profundos durante a vida intra-uterina secundária a trauma cirúrgico (amniocentese, por exemplo) ou acidental ${ }^{3}$.

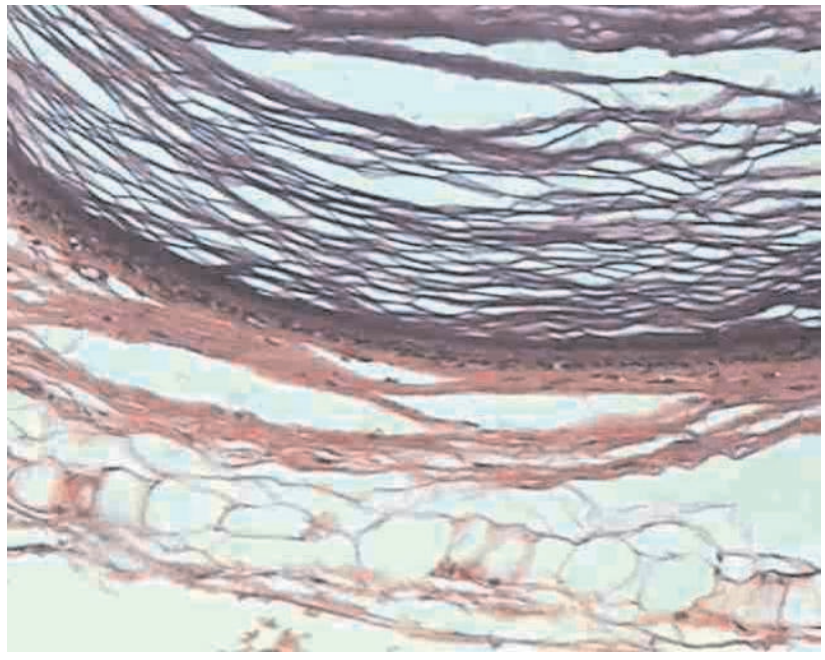

Figura 2 - Exame microscópico mostrando formação cística com parede constituída por epitélio plano estratificado com diferenciação em camadas granulosa e córnea, ausência de sinais de malignidade e compatível com cisto dermóide.

Com relação à localização, os cistos dermóides se apresentam mais comumente na região cervical e cabeça ${ }^{3}$.

O caso relatado evidenciou a presença de um cisto dermóide na região retro-retal, no qual simulava uma neoplasia.

Desse modo, os cistos dermóides devem ser considerados como diagnóstico diferencial de massas retro-retais, cujo diagnóstico conclusivo só será dado com anátomo-patológico, devendo no intra-operatório serem seguidos os princípios oncológicos.

ABSTRACT: Dermoid cyst is a tumor formation composed of an epidermal enclousure which contains pilous follicle and sebaceous glands. Generally it is located on the neck.

Key words: Dermoid cyst; neoplasia; retro-rectal; benign, retal touch.

\section{REFERÊNCIAS}

01. Filho,G.B.; Pittella,J.E.H.; Pereira,F.E.L.; Bambirra,E.A.; Barbosa,A.J.A. Bogliolo Patologia. Quinta edição, 1994, ed. Guanabara koogan, Rio de Janeiro, RJ.

02. Sampaio,S.A.P.; Rivitti,E.A. - Dermatologia. Segunda edição, 2001, ed. Artes Médicas, São Paulo, SP.

03. D' Antônio,W.E.P.A.; Ikino, C.M.O.; Murakami,M.S.; Sennes,L.U.; Tsuji, D.H. - Cisto epidermóide gigante de assoalho de boca. Rev Bras Otorrinolaringologia. Vol. 66, edição 1 (jan-fev), 2000.
04. Braunwald,E.; Isselbacher,K.J.; Wilson, J.D. et al. - Harrison Medicina Interna. Décima quarta edição, 1998, ed. MacGrawHill, Rio de Janeiro, RJ.

\section{Endereço para correspondência:}

ERLON DE ÁVILA CARVALHO

Rua João da Mata, 153, Bairro Bonfim, São João Del Rei, MG $\mathrm{CEP}=36307-444$

E-mail: ehawilla@yahoo.com.br

Tel: (32) 3371-2192 